\title{
A Comparative Analysis of the Differences of Family Education between China and America
}

\author{
Caiqiao Huo, Xinfa Yuan \\ Foreign Language Department, Baoding University, Baoding, China \\ Email:goofyhuo@163.com
}

Received 11 June 2015; accepted 10 July 2015; published 13 July 2015

Copyright (C) 2015 by authors and Scientific Research Publishing Inc.

This work is licensed under the Creative Commons Attribution International License (CC BY). http://creativecommons.org/licenses/by/4.0/

(c) $\underset{\mathrm{EY}}{\mathrm{B}}$ Open Access

\begin{abstract}
Family is the first place where children receive education, so family education has a great influence on one's life. This paper is about the family education in China and America. It compares the differences from the aspects of methods, contents, objectives and results of family education between China and America. Then, it analyses the reasons for the differences in family education. Finally, some suggestions for family education in China are provided.
\end{abstract}

\section{Keywords}

Family Education, Differences, Suggestions

\section{Introduction}

In one's lifetime, the family is the first school. The earliest education is also the longest and most profound one. As the world develops, many countries take education seriously, especially the family education. Although family education now attracts social circle's attention, especially educational circle's attention, Chinese family education still has a lot of problems. To find a better way to educate Chinese children, Chinese parents should study other countries' experiences. American family education is the most famous one of all kinds of family education, so it is necessary and significant to make a comparison of the differences of family education between America and China. Then, what are the differences of family education between America and China, and what is the cause of these differences? By contrasting the family education of America and China, this paper will tell the differences of family education between the two countries and interpret the reasons for these differences. Through the comparison, this paper also puts forward some suggestions that suit Chinese family education. 


\section{A Comparison between American Family Education and Chinese Family Education}

\subsection{A Comparison between Family Education Objectives}

Family education objectives impose restrictions on its orientation and decide its overall results. Therefore, they form the core of family education and the basic cause for the differences between the two countries in family education.

The objective of American family education is to raise children as social people who are able to conform to the different surroundings and are independent. They generally believe that children's growth must rely on their own experiences, because they think that children should form a self-supporting will and the capacity to live independently from their childhood to adulthood. Being social people is not just the whole thing; it is a basic and essential requirement. So the parents can easily develop the active elements in the children's characters to the greatest degree. In this case, children can realize their own personal worth without considering the utilitarian objectives, such as high academic degrees and well-paid jobs. Actually, this type of education often produces unexpected results. On the other hand, guided by this objective, children are trained to be more independent in thinking and action. This can be seen from each stage of American children in their growth: when they are infants, they sleep by themselves; when they can walk, they play by themselves; and when they grow older, they have their own rooms and they decorate and clean them all by themselves. They do paid work within their reach when they are young, such as cleaning, taking care of babies and delivering newspaper, etc; when they are in high school and university, they are on work-study programs and support themselves.

Compared with American parents, Chinese parents have a very different aim for their children's education. They are eager their children to become someone, to have good jobs and live in an easy life. To achieve this objective, Chinese parents care most about their children's grade point average. They have a rather strict attitude towards their children's study and regard the grades as the only standard for future success. Chinese parents tend to ignore children's talents and restrict their creativity. Some parents in China only care about whether the children have a promising future, a good job, a good life and don't care about their personality and competence to conform to society. Thus, few of the children will be successful though they do well in school (Wang, 2006: p. 70). The majority of Chinese parents feel that their responsibility for their children is to create the best possible conditions. They would like to provide everything that they can for their children in the process of their child's growth. In a word, Chinese parents would like to sacrifice anything if their children can live better with their help. Chinese parents care little or not at all about their children's independence, civic awareness and their ability to adapt to the society in the future, Chinese parents care little or not at all.

\subsection{A Comparison between Family Education Methods}

Different aims in family education lead to distinguished methods in fostering children. The following will focus on the different approaches to American and Chinese family education.

In America, parents are more likely to adapt to a method of equality in this process. Most American parents don't formally educate their children specifically in anything but to provide them with background information allowing them to choose. Besides, unless serious issues happen, they seldom interfere with their children's private lives. American parents also encourage their children to find the value between spending and saving. And this is a way to earn one's own respect. When kids become adults, most of them leave the house and begin an independent life. American parents consider it natural to let go. In America, in addition to their studies, parents want their children to be involved in many other activities. They want children to be in good health, so they will ask their children to do more out-door exercises. They will not help their children choose what sports to do; children can decide on their own. American parents know the importance of the emotional quotient, so they coordinate the emotional quotient with intelligence quotient. Thus, children can have a comprehensive development. Moreover, American parents prefer to cultivate the initiative, creation and leadership of their kids, rather than persuade them to follow traditions.

Compared with American parents, Chinese parents are the instructors and obedience is commonly praised in fostering children. Mostly, when parents are talking with their children, words like "do not", "should not", appear repeatedly. And most children accept their parents' words as golden rules to behave and socialize. Some even view their parents as authority. Besides, Chinese parents are more likely to have their children stay around. Chinese parents often want to educate their children to become a successful person and sometimes they don't 
take their children's real situations into consideration. Chinese family education provides less chance for children to choose what they want as a result of our exam-oriented education. Chinese students have a well-established learning foundation and a good self-discipline since Chinese parents pay more attention to kids' intelligence quotient. However, Chinese family education also has short-comings. First, the spoiled raising method, which means parents are often satisfying their kids wishes. In contemporary society, "boomerang child", "strawberry generation" and "child slave" become high frequency words used to describe Chinese parents. Second, parents only emphasize the intelligence quotient and completely ignore the emotional quotient. Spending a lot of time on the intelligence quotient and ignoring the emotional aspects, many children in China become weak-willed.

\subsection{A Comparison between Family Education Contents}

There are many differences in the contents of moral education, intellectual education and physical education. Besides, since the sex problem has been a heated issue today, it's fit and proper for us to discuss sex education.

\subsubsection{Moral Education}

As a foundation for the moral education, the loyalty and the filial obedience maintain unequal relation in feudal society. Under the influence of regulations for feudal religion, traditionally Chinese moral education is different from other countries' moral educations. However, America is a representative of a capitalistic country, and people hold a view point of the moral education with equalities of a personality, a democracy, a freedom and a fraternity (Musgrove, 1966: p. 102).

\subsubsection{Intellectual Education}

In China, a well-rounded education usually consists of moral, intellectual, physical and artistic education. From the time a child starts school, intellectual education comes first in the eyes of both children and parents. The center of family education turns away from survival and morality to intelligence and performance. While, American family education pays more attention to children's all-around development, including language, religion, cognition, comprehension, emotion, survival skills and other techniques (Wu, 2003: p. 358).

\subsubsection{Physical Education}

Compared with American parents, Chinese parents are concerned more about intellectual development rather than physical development. In China, children are often educated on how to get high marks and how to enter a famous university. In Chinese family education, physical education is less important than intellectual education. Most Chinese children have to take remedial classes after school.

In contrast, in American family education, children are encouraged to participate in the work personally and complete the project together instead of spending the whole day working silently and alone, which is very helpful to enhance children's physical strength and team spirits (Emmannel, 2006: p. 111). American parents take their children to play sports, or even organize, coach and train the children. Their aim is not to make their children be a winner, but to make their children learn how to face challenges, cooperate with others, and build up their children's bodies.

\subsubsection{Sex Education}

Sex education in china is limited and falls behind the fast developing society. Sex education is almost a taboo in family conversations. Some parents even scold their children for asking such questions, suggesting sex is still a sensitive topic in our daily life. In China, there are no formal and useful publications about sex education for children (Wang, 2014: p. 14).

Americans do better in sex education. American children have sex courses at school and some parents talk about it at home. In American parents' view, talking about sex will embarrass the kids, but they understand it's necessary to teach them sex education. Teaching sex education to children help them learn more about sex in a more scientific way. American parents' healthy attitudes toward sex as well as their factual answers help their children grow in many ways.

\subsection{A Comparison between Family Education Results}

Generally speaking, children in the United States usually show the following characteristics: American children 
tend to be active, they can keep calm when they are in trouble, can live with people in harmony, optimistic, brave, have the fortitude to overcome difficulties, dare to think, dare to do, have the spirit of innovation. They are strong in self-reliance; strong in social activities, have the confidence and courage to be a social individual (Erikson, 1993: p. 165). Most American children become less reliant on their parents when they turn 18 years old. Whether their families are rich or poor, they might find part time jobs to provide for their own needs, and learn to adapt to the market economy.

As for Chinese children, although their academic records are not inferior to the American children, they often display the negative tendency in their disposition. For example, working passively, getting into the habit of relying on their parents, developing weak human communication skills, and they are deficient in their ability to be independent. Perhaps the individualities and characteristics of Chinese children have a close connection with the favor of "school record education" within the society. So Chinese parents care for children's achievements at school very much, but they ignore children's interests, talents and creativities.

\section{Analysis of the Reasons Causing These Differences in Family Education}

\subsection{Historical Backgrounds}

The United States is a nation of immigrants with a short history, where old-fashioned ideas are seldom preserved and new ideas are accepted easily and developed unrestrictedly under the influence of multi-cultural values. Affected by multi-culture and multi-value, it can accept new thoughts and culture more quickly without restriction (Hall, 1996: p. 131). So compared to the Chinese people, they possess a more adventurous and creative spirit. However, China has a long history, and it preserves more old culture, especially affected by feudal farmer's idea for a long period. Its cultural values are conservative and cautious, which lacks an adventurous spirit and creative consciousness. Chinese people are educated to be obedient, comparative and lack an environment to accept new ideas on the whole.

\subsection{Social Systems}

In China, one main point of Socialism is the government should try to distribute the social resources fairly. People in this social structure emphasize family-oriented or group-oriented ideas. Although in modern society, people were attracted by economic interests, but we still act very modest when it comes to personal interest. America has a totally different social system, that is Capitalism, and people influenced by this social system pay much more attention to individual's interests. They focus on personal development and advocate individualism. Influenced by this social system, they are more independent. The main spirit of their society is personal achievement.

\subsection{Economic Patterns}

The United States, with an advanced productive force, a booming economy, and a society of capabilities, contains an ideal system where staff is free. In addition, they have many opportunities for changing jobs. This suggests there are various jobs for Americans to choose. But China is an academic-oriented society with a backward economy, in which living with stress is heavy. People tend to place the happiness of their whole life on one vocation. Chinese parents believe that the best way to live life is by doing well both in their studies and finding a good job. As a result, the objective of Chinese family education is to receive a higher education and obtain a better job.

\subsection{Cultural Traditions}

Americans' orientation is based on individualism. They lay stress on their own benefits, advocate individual improvement and find their own true value. It is the core of American culture (Di, 2001: p. 90). To carry out children's self-value, parents should respect children's willingness, interest and hobby first. American parents attach importance to enjoying their life. Chinese pay attention to general character. They have a conception, which is the most important, the conception is a collective spirit (Bond, 1986: p. 106). In the Chinese family, parents lose themselves in their children, and paradoxically don't respect them. The way that Chinese parents lose themselves is as follows: they consider children as their own, as a continuation of themselves; their children seem to be their whole lives and hopes; they put all their hopes on their children. 
Americans are so rational that their family education is focused on treating the family members and affairs rationally. In their views, the obligations of fostering and educating children are equal to those of the society, not starting from the interest of the whole families and themselves. In Americans' opinions, family education is considered an obligation. Most Chinese parents educate their children out of the consideration of supporting them through old age to realize their own ambitions, since they regard children as their personal properties.

The relationship among family members in America is quite different from that in China. As the above mentioned, the American emphasizes individualism, therefore, the relationship between family members is very simple, and everyone is equal. And when children grow up, most parents couldn't interfere with their children's decisions. Parents can only give their children some guidelines based on their experience to help influence children's final decisions to some extent (Zhu, 1997: p. 185). Comparatively, it's much more complex in China than in America. Chinese people are deeply influenced by Confucianism; therefore, they try to show their respect to the elders in their daily life. Frankly speaking, the relationship between family members is not always equal in most Chinese.

\section{Suggestions for Chinese Family Education}

In this comparative study on family education in China and America, to some degree, it's obvious that American family education is superior to Chinese family education. Hence, to have a better systematic way for raising children, Chinese parents can draw lessons from the American way. Of course, compared with Chinese family education, there is also distinctiveness on American family education. All in all, Chinese family education and American family education have their own characteristics, so the aim of this thesis is not totally to repudiate Chinese family education or wholly to accept American family education. In the end, by this comparative study on family education in China and America, the writer wants to encourage and cause reform for ideas toward Chinese family education in order to improve Chinese education level.

\subsection{Revolution in Traditional Family Ideas}

According to our country's special circumstances, the number of one-child family is becoming larger, so family education must be improved toward educational reform and development. Family education must be combined with school education and social education, thus, demonstrating a need to change traditional family ideas.

\subsection{Conversion in the Cultivation of Children's Fame}

Parents' wrong values and wrong behaviors can affect their children deeply. Chinese parents should attach more importance to their children's independence, mental health, morality and civic awareness, by helping their children not only to master the knowledge and wisdom learned but also shape their will power and psychology.

\subsection{Combination of the Two Kinds of Family Education}

The difference between Chinese and American family education call forth more and more people to be concerned with how to improve family education. In fact, much can be learned from each other regarding the ways of family education for China and America. In modern society, with the help of many scholars, family education has already permeated into various aspects of human life. When Chinese parents combine the American family education methods and Chinese family education methods, they must pay attention to the different features of family education between America and China. Only by doing like this can Chinese children grow healthily and strongly.

\section{Conclusion}

Education is a highly complicated process that is connected with families, schools and society throughout one's whole life; family education is an important part of the whole education system. It is the modern society who can present its special education function as the basic power to usher society toward the creation of family happiness.

\section{References}

Di, Y. H. (2001). American Culture. Changchun: Jilin Science \& Technology Press. 
Hall, E. T. (1996) The Hidden Dimension. New York: Double-Day.

Erikson, E. H. (1993). Childhood and Society. New York: Norton.

Musgrove, F. (1966). The Family Education and Society. London: Routledge \& Kegan Paul.

Emmannel, J. (2006). Development and the Next Generation. Washington DC: World Bank.

Bond, M. H. (1986). The Psychology of the Chinese People. New York: Oxford University Press.

Wang, X. H. (2006). Comparison of the Difference of Family Education between China and America. Journal of Liaoning Education Administration Institute, No. 1, 69-71.

Wang, J. J. (2014). Analysis of Sex Education in Children from Sexual Assault. Journal of Educational Institute of Jilin Province, No. 11, 14-15.

Wu, F. (2003). American Society and Culture. Wuhan: Wuhan University Press.

Zhu, Y. T. (1997) The Society and Culture of Major English-Speaking Countries. Beijing: Higher Education Press. 